\title{
THE PAIN DRAIN
}

We can't live without it, but many of us struggle to live with it. Pain has an essential biological function, but too much - or the wrong sort - ruins lives and puts a sizeable dent in economic productivity. By David Holmes, infographic by Mohamed Ashour.

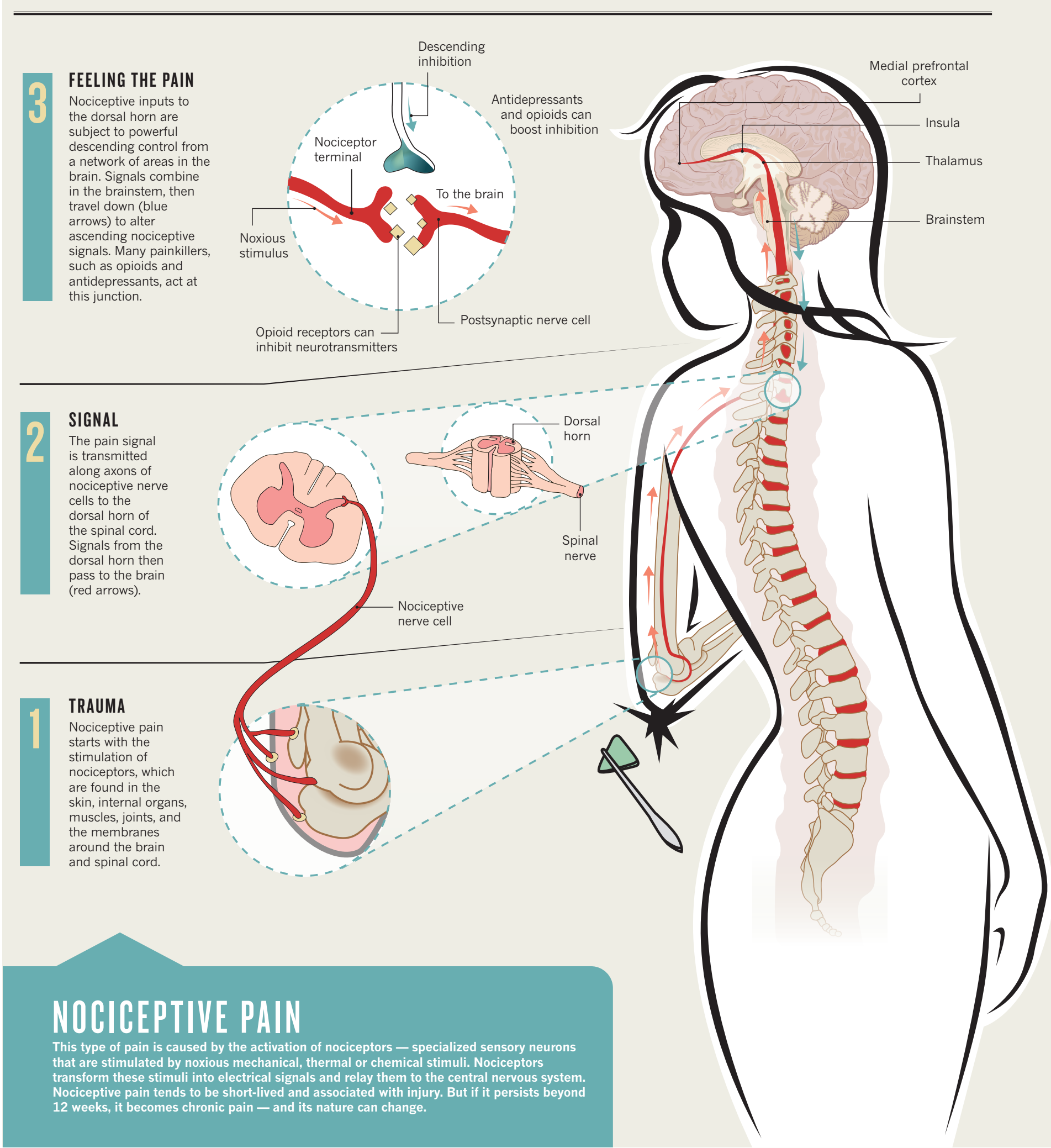




\section{NEUROPATHIC PAIN}

Unlike nociceptive pain, neuropathic pain is caused by damage to the somatosensory nervous system itself, as a result of trauma or disease.

However, there is not always a clear link between disease states and neuropathic pain.

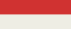

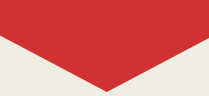

\section{DIABETIC NEUROPATHY}

Painful diabetic peripheral neuropathy is one of the most common forms of neuropathic pain, with its incidence set to increase as the obesity and diabetes epidemics continue to grow. Neuropathy is caused by metabolic factors as well as by damage to the microvasculature that supplies nerve fibres.

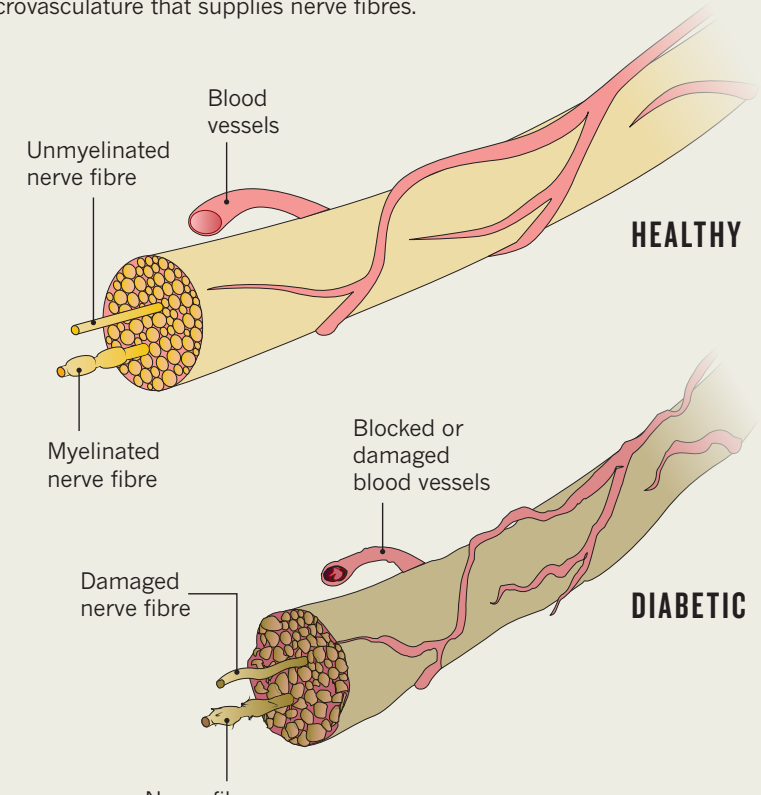

Nerve fibre loses myelin

\section{NEUROPATHIC PAIN INCIDENCE}

Definitions of neuropathic pain vary across studies, leading researchers to call for a unified nomenclature. The best evidence on incidence comes from studies of neuropathic pain linked to specific conditions, but even then ranges can

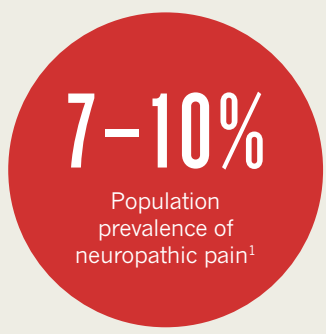
vary widely ${ }^{1}$

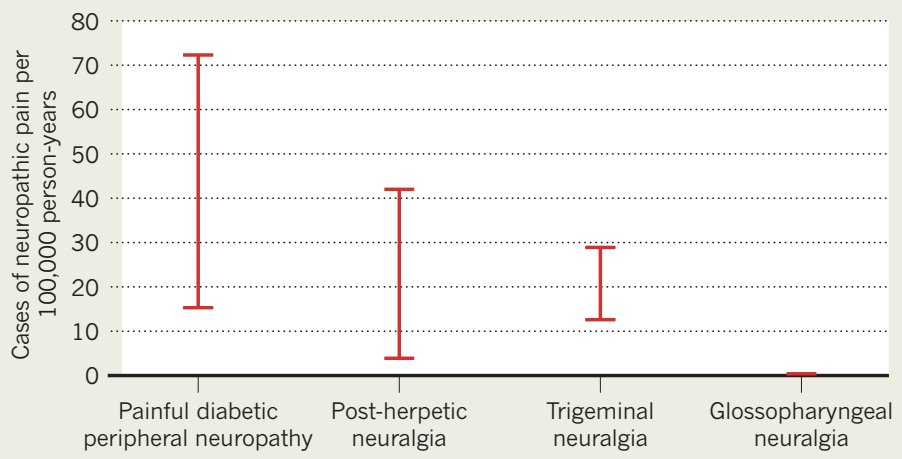

\section{PRICE OF PAIN}

\section{BIGGEST BURDEN}

Around 100 million adults in the United States are affected by chronic pain in a single year. The annual total cost of pain, including direct costs, decreased wages and lost productivity, eclipses that of any other condition?2.
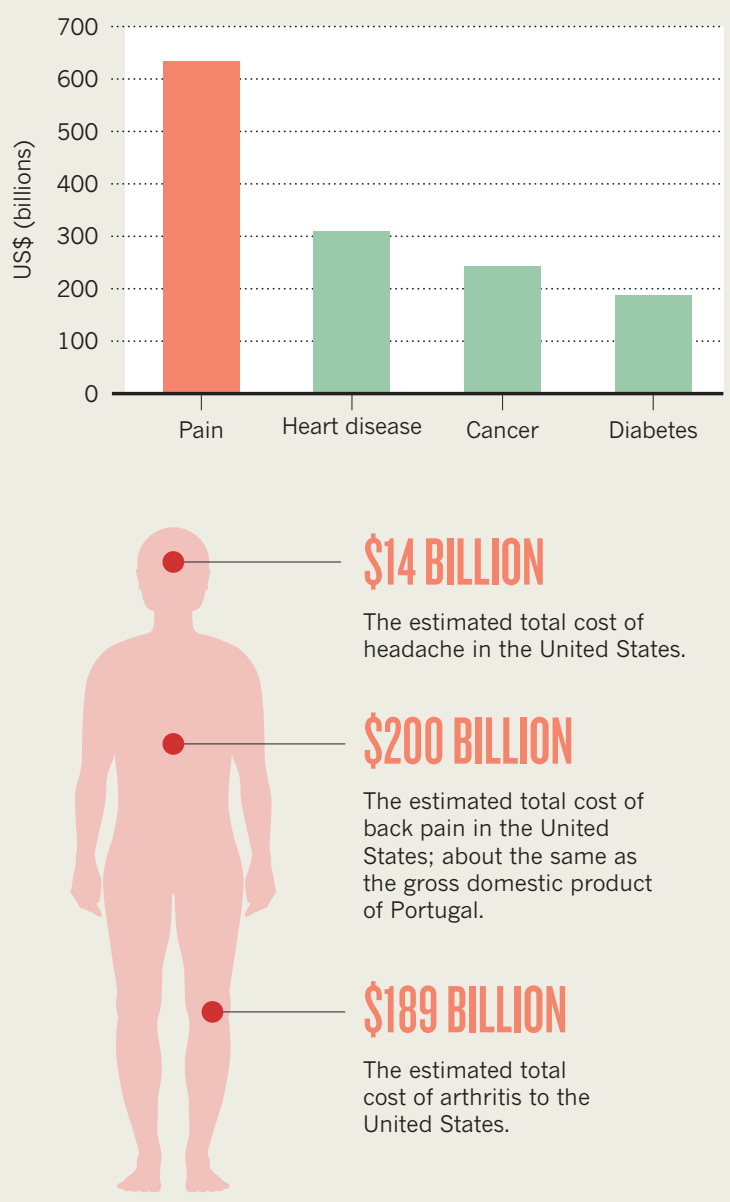

\section{\$14BLLLION}

The estimated total cost of headache in the United States.

\section{\$200B|LLION}

The estimated total cost of back pain in the United States; about the same as the gross domestic product of Portugal.

\section{\$189 BILLLON}

The estimated total cost of arthritis to the United States.

\section{GROWING PAIN}

Health-care spending on back problems in the United States more than doubled between 1987 and 2000. Although treatment costs and population increases contributed, most of the $\$ 9.5$-billion rise was due to an increase in the prevalence of back pain ${ }^{3}$.

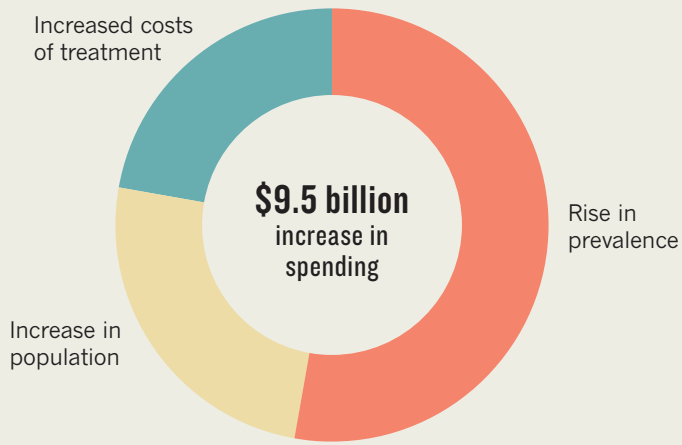

